Resumen por el autor, Charles Martell Wilhelmj, Escuela Médica de la Universidad de San Luis.

Un caso de desplazamiento cruzado del riñón con fusión.

El riñon izquierdo está desplazado hacia el lado derecho, y su polo superior está fusionado con el inferior del riñón derecho. El uréter del riñon derecho sigue prácticamente su curso normal. El del riñón desplazado pasa hacia la izquierda por detrás del colon pélvico y la arteria hemorroidal superior, entrando en la vejiga por el lado derecho. Los vasos del riñón derecho no presentan caracteres anormales. El riñon desplazado está irrigado por dos arterias, una que nace de la aorta, prácticamente en común con la arteria mesentérica inferior; la segunda arteria fué cortada durante la disección sin poder determinar exactamente su orígen. Del riñón desplazado parten dos venas, de las cuales la mas pequeña e inferior es tributaria de la vena cava inferior, en el comienzo de esta última; la vena superior y mas grande tuerce hacia la izquierda por debajo de la arteria mesentérica inferior, pasando hacia arriba para desembocar en la vena cava en el sitio de costumbre. La longitud es de $12.5 \mathrm{~cm}$. Esta vena probablemente está formada en parte por una sección persistente de la vena cardinal posterior izquierda, situada entre el punto de entrada de una vena renal anormalmente baja y la anastomosis que reune las venas cardinales y subcardinales. Ambas glándulas suprarrenales estaban situadas normalmente.

Translation by Jose F. Nonidez

Carnegia Institution of Washington 
ACTHOR'S ABSTRACT OF THIS PAPER ISBTED

\section{A CASE OF CROSSED DISPLACEMENT OF THE LEFT KIDNEY WITH FUSION}

C. M. WILHELMJ

Department of Anatomy, St. Louis University Medical School

TWO FIGURES

ANATOMICAL DESCRIPTION

\section{Position of the Kidneys}

The left kidney is displaced to the right side and lies inferior to the right kidney. The right kidney is abnormally low, its lower pole overlapping the crest of the ilium and extending about 2.5 cms. below it. The upper pole of the displaced left kidney is on about the level of the iliac crest, medial to the lower pole of the right kidney, while its lower pole extends down to the level of the fifth lumbar vertebrae and slightly overlaps the right common iliac artery. The medial extremity of the left kidney overlaps the Inferior Vena Cava, (fig. 1).

\section{Size and Shape}

a Right Kidney. Length: $8.75 \mathrm{cms}$. Circumference $12.5 \mathrm{cms}$.

b. Left Kidney. Length: $7.5 \mathrm{cms}$. Circumference: $15 \mathrm{cms}$. Width: $6.9 \mathrm{cms}$. Thickness: $1.7 \mathrm{cms}$.

The right kidney is normally shaped and the hilus is directed medially. The left kidney is very much broadened in the coronal and flattened in the sagittal direction. It appears to be split open, with an extremely large hilus on the anterior surface, which extends practically from the upper to the lower pole and its greatest width, which is at the middle, is about $2.1 \mathrm{cms}$. On account of the extreme thinness of the kidney and the large hilus, the sinus is very shallow and practically wide open on the surface. The 
hilus and sinus divide the anterior surface of the kidney into two distinct parts, the lateral division being semilunar in shape with the concavity directed medially, while the medial portion is somewhat quadrangular shaped, being $2.8 \mathrm{cms}$. wide and $5.6 \mathrm{cms}$. long. On the anterior surface these two parts appear to be entirely

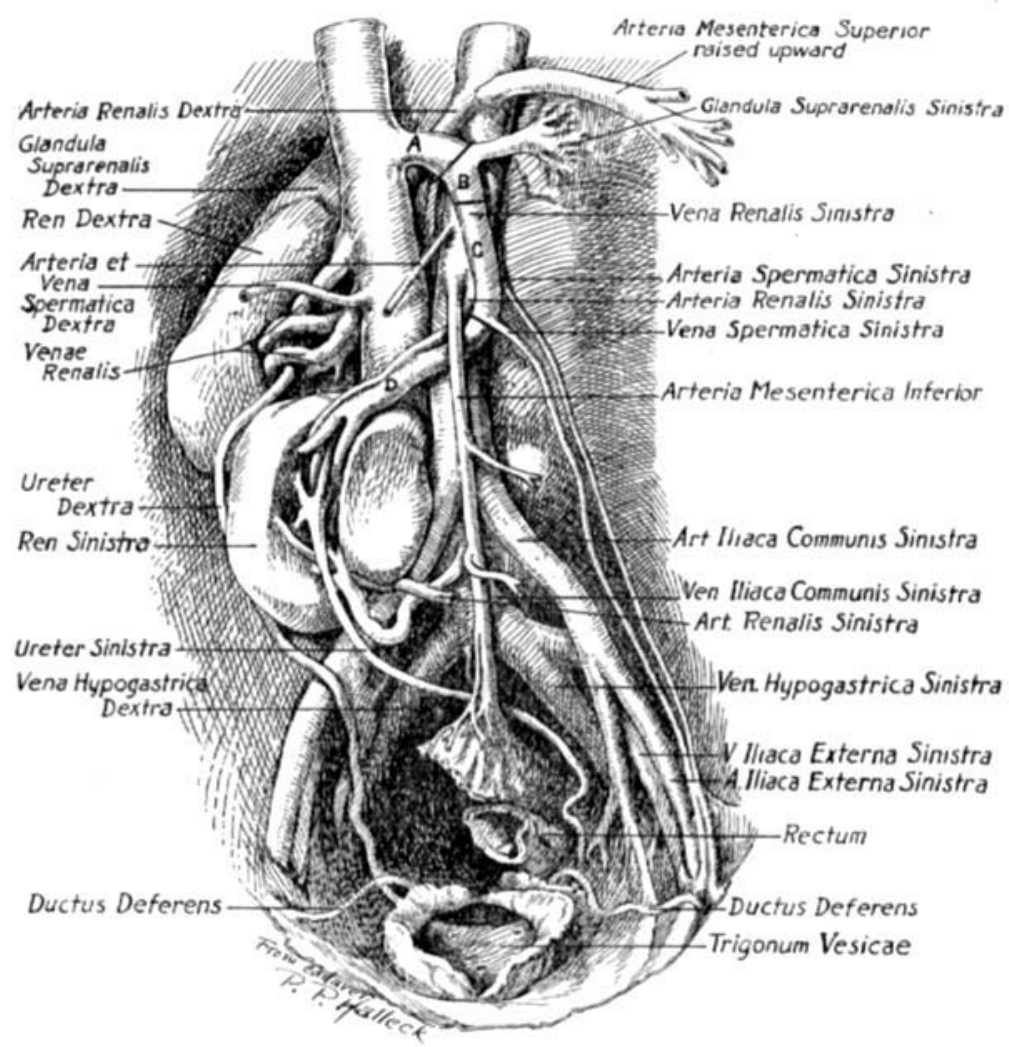

Figure 1

separate from each other, but on the posterior aspect, which is flat and very smooth, there is no sign of any demarcation between them.

\section{Vessels of the Right Kidney}

a) Arteries. A single artery is given off from the aorta which passes downwards and laterally, posterior to the Inferior Vena 
Cava, at the lateral extremity of which, it bifurcates into two large terminal branches. The smaller and most anterior of these branches passes between the two upper and the two lower renal veins and anterior to the pelvis of the ureter, it then enters the hilus at its extreme ventral limit. Just as it sinks into the sinus it breaks up into one large and one small terminal branch. The larger and more posterior terminal branch of the renal artery enters the hilus near its upper limit, deep to all the other structures, and also gives off a small branch which passes between the two upper renal veins and enters the upper and ventral limit of the hilus.

b) Veins. Four rather large veins emerge from the hilus, which can be classified into an upper and a lower pair. The two upper veins, between which the last mentioned small artery passes, soon unite to form a large vein which passes upwards and medially, anterior and parallel to the right renal artery, to enter the Inferior Vena Cava. The smaller of the lower pair of veins emerges from the hilus with the first branch of the renal artery described, and then passes upwards and medially, parallel to that artery and anterior to the ureter, to enter the Inferior Vena Cava. The second of the lower pair of veins, the largest of the four, is deeply placed and emerges posterior to the ureter, it then passes upwards, posterior and parallel to its mate, and the two enter the Inferior Vena Cava practically by a common orifice.

\section{Vessels of the Displaced Left Kidney}

a) Arteries. There are two main arteries. The upper and larger one arises from the aorta on the same level and just to the left of the Inferior Mesenteric Artery. It then swings under the Inferior Mesenteric Artery and passes horizontally and to the right along the upper border of the displaced kidney. When it reaches the upper limit of the hilus it turns and passes downward along its lateral edge and sinks into the sinus at about the junction of the upper one-third with the lower two thirds of the lateral margin. Before it turns downwards, while it is still passing parallel to the upper border of the displaced kidney, it gives off 
four branches, three of which are very short and immediately enter the upper part of the medial quadrangular division of the kidney. The fourth branch turns and passes downward along the medial margin of the hilus, and enters the sinus on about the same level as the main branch. Therefore the upper one third or half of the hilus has an artery running along both its lateral and medial margin. The lower Left Renal Artery is much smaller. Unfortunately the student who dissected the body broke it, and I was unable to determine its exact origin, but from its relations it must have been a branch from one of three arteries; either the Right or Left Common Iliac or the Inferior Mesenteric. It passes to the right, anterior to the Right Common Iliac Artery, and at the lower margin of the left kidney gives off several small branches which enter the lower pole of the medial quadrangular portion; the main trunk then swings into the lower part of the hilus and passes upwards along the lower two-thirds of its lateral margin, where it enters the sinus. The margins of the hilus are, therefore, surrounded by arteries, with the exception of the lower medial two-thirds.

b) Veins. Are arranged in two sets: The two upper veins correspond to the arteries, one running along the lateral and the other along the medial margin of the hilus; the medial vein, however, has a longer course than the corresponding artery; it runs along the whole extent of the medial and also the lower part of the lateral margin of the hilus and has, therefore, a $J$ shape. These two veins unite at the upper limit of the hilus to form a very large vein. The course of this vein is one of the most striking peculiarities of the specimen. It passes horizontally and medially and after swinging under the Inferior Mesenteric Artery, runs upward on top of the aorta, to about the level of the upper pole of the right kidney, where it turns to the right and enters the Inferior Vena Cava at about the normal level for the Left Renal Vein. Its total length is a little over $12.5 \mathrm{cms}$. While it is still on top of the aorta, just as it turns to the right to enter the Inferior Vena Cava, it receives the large left suprarenal vein, and just before it passes under the Inferior Mesenteric Artery, it receives the Left Internal Spermatic Vein. The smaller 
and lower vein is made up at the inferior margin of the hilus and runs to the left with its companion artery, anterior to the Right Common Iliac Artery, to enter the beginning of the Inferior Vena Cava.

\section{Other Vessels}

The Inferior Vena Cava is formed lower than normal, at about $2.5 \mathrm{cms}$. below the bifurcation of the aorta, or at the upper part of the fifth lumbar vertebra.

The Right Hypogastric Vein instead of joining the Right External Iliac, enters the Left Common Iliac Vein; so that a Right Common Iliac Vein is not present.

The Left Supra-Renal Vein is very large, and is made up by a collection of small veins which emerge from the gland.

Spermatic arteries and veins are normal.

\section{Suprarenal Glands}

The Right Suprarenal has its normal relation to the upper pole of the Right Kidney. Left Suprarenal Gland is normally placed and is on about the same level as the right.

\section{Ureters}

a) Right Ureter. The ureter from the right kidney emerges from the hilus and swings downward and somewhat laterally in a shallow groove between the fused parts of the two kidneys, making a curve with the convexity directed upwards and laterally; it then turns downward and runs just under the lateral edge of the displaced kidney. Continuing downwards, it emerges from under the left kidney and crosses the Right Common Iliac Artery at its point of bifurcation and descends into the pelvis slightly anterolateral to the Hypogastric Artery, finally entering the bladder in a perfectly normal manner. It is crossed by the Ductus deferens on the level of the spine of the ischium, and has the correct relation to the Seminal Vesicles.

b) Ureter from the Displaced Left Kidney. Four calyces unite to form a very small pelvis, which is exposed to the surface in the 
shallow sinus. The ureter passes downwards leaving the sinus at the inferior pole of the kidney, and passing gradually to the left, it lies anterior to the Right Common Iliac Artery and the displaced Right Hypogastric Vein, and posterior to the lower part of the pelvic colon and the Superior Hemorrhoidal Artery. Still passing to the left and downward it comes to lie anterior to the Left Hypogastric Vein and medial to the artery, and then continues downwards to a perfectly normal entrance into the bladder on the left side. Its relation to the Ductus deferens is normal. The trigonum of the bladder is also normal.

\section{DISCUSSION}

This case probably represents one of the rarest of kidney anomalies. According to McMurrich, Birmingham states that Morris has seen it only once in 14,318 autopsies. McMurrich in reporting his case gives an excellent summary of all the cases reported up to that time. He cites in all just 28 cases, and states that only 26 of these can be considered as true examples of crossed dystopia.

Any attempt to fully explain the embryonic causes for this anomaly would, of course, be practically without foundation, considering the present nebulous state of our information on the subject, but certain interesting similarities in these cases have been pointed out. McMurrich states that in 83 per cent of cases, the ureter from the upper kidney opens into the right side of the bladder when the fused organ is on the right side, and into the left side of the bladder when the fused organ is on the left side. This means that in 83 per cent of cases the displaced kidney has been retarded in its upward migration. Just what this retardation may have to do with its subsequent displacement is hard to say, however, the time element, which is so prominent a factor in all embryonic activities, cannot be overlooked. When an organ has failed to migrate at the proper time it is at once subjected to the influence of adjacent organs, which under normal conditions, would not have affected it. In the case of a retarded kidney, at least three such foreign influences may play a part in its displace- 
ment: first, the rotation of the gut when it begins to assume the adult position; second, the great increase in size of the caudal end of the Wolffian body, which would not affect a normal kidney because it would have already migrated towards the cranial end of this organ, which is already undergoing degeneration and decreasing in size; and thirdly, the descent of the sex gland.

In the present case we may safely state that the displacement occurred before the rotation of the intestine, because of the relation of the left ureter to the pelvic colon and the relation of the left Renal Vein and Artery to the Inferior Mesenteric Artery.

Jeidell, in his work on the vascularization of the kidney, has shown that in $14 \mathrm{~mm}$. pig embryos, the Inferior Mesenteric Artery gives off what may be considered, as the main temporary artery to the growing kidney, and since the main artery to the displaced kidney in this case arises from the aorta practically in common with the Inferior Mesenteric, we may again roughly determine the time at which the displacement occurred. According to Jeidell's work, the Renal Veins at this same stage are tributaries of the Posterior Cardinal Veins.

The length and course of the Left Renal Vein can only be satisfactorily explained by considering the primitive venous system of this region and its later metamorphosis. The early veins to be considered are the two Posterior Cardinals, the two Subcardinals, and the Hepatic Veins, and the various anastomoses which take place between them. At its cranial limit each Posterior Cardinal joins the corresponding Anterior Cardinal to form the Ductus Cuvieri; while inferiorly each is made up by the union of the corresponding Internal and External Iliac Veins. In addition each Post. Cardinal receives the Mesonephric Veins; the temporary, and later the permanent, renal veins. The Subcardinals lie on the ventral surface of the mesonephros and each may be considered as being formed by a ventral anastomosis between the mesonephric tributaries of the Post. Cardinal; hence each Subcardinal joins the corresponding Post. Cardinal both cranially and caudally, while between these two limits there are many anastomoses between them. There are also many connections between the two Subcardinals across the aorta (fig. $2 \mathrm{~A}$ ). The first im- 

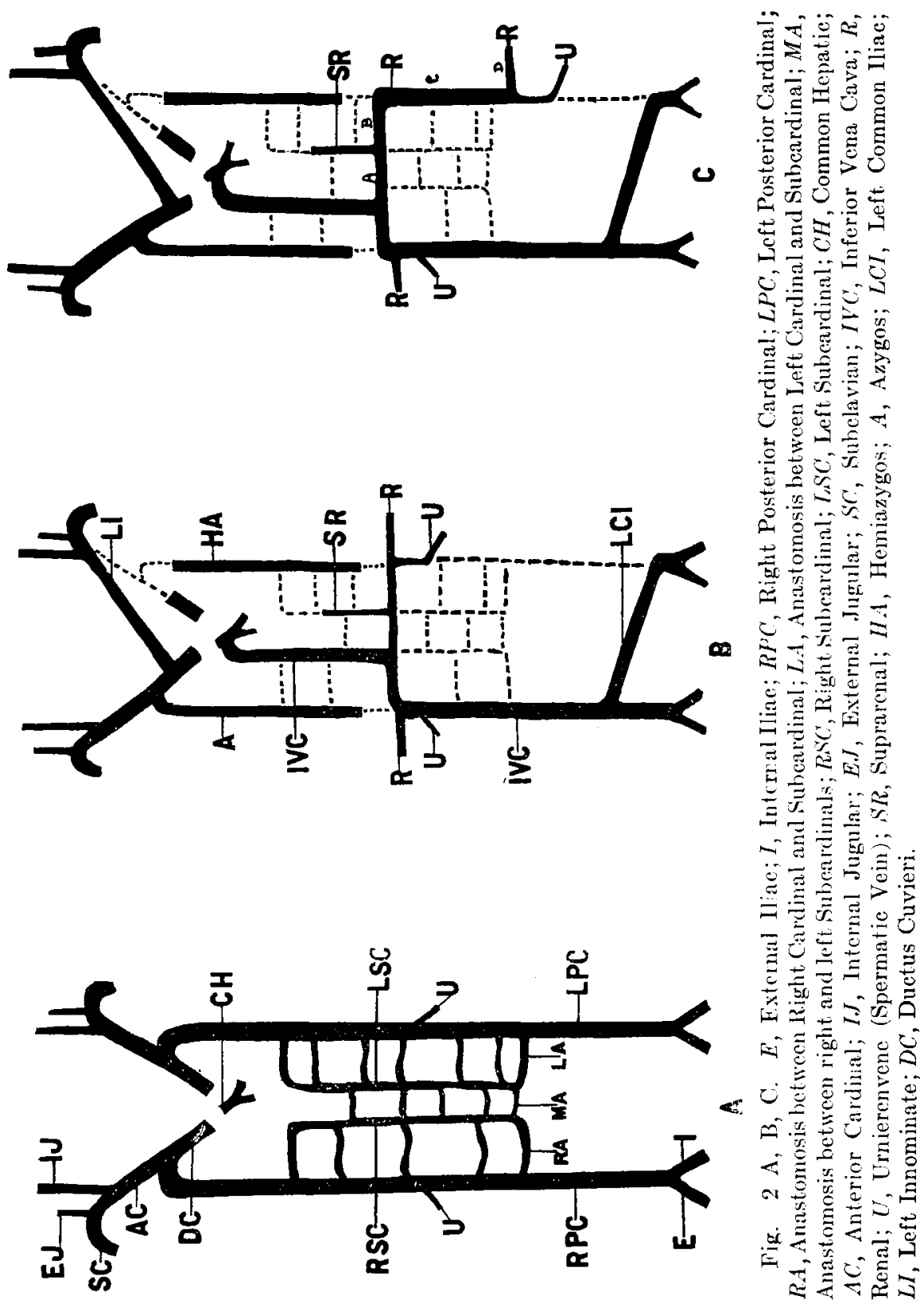
portant change consists in an anastomosis between the cranial end of the Right Subcardinal and the Common Hepatic Vein in the caval mesentery, by which a new channel is established to the heart independent of the Ductus Cuvieri. Following this, the connecting trunk across mid-line between the two Subcardinals, which lies just caudal to the Superior Mesenteric Artery, begins to predominate over other similar trunks. On each side, and on the same level, one of the anastomoses, between the corresponding Cardinals and Subcardinals, also shows a similar enlargement. Thus a trunk is formed across mid line which connects these four veins at the level at which the future permanent renal veins join the Post. Cardinals. The third step consists in the formation of the Left Common Iliac, which connects the lower parts of the two Post. Cardinals. It is also necessary to call attention to a small vein, the "Urnierenvene" of Hochstetter, which enters the Post. Cardinal just below the level of the future permanent renal vein (fig. $2, \mathrm{~A}$ ).

The final establishment of the adult condition consists in degeneration and loss of connections between certain of these veins. The segment of both Subcardinals below the transverse anastomosis, probably degenerates completely. The upper part of the left Subcardinal, according to Hochstetter, remains as the left Suprarenal Vein, fig. 2 B; while the upper portion of the right constitutes a part of the adult Inferior Vena Cava. The portion of the transverse anastomosis, which lies to the left of the Right Subcardinal, remains as a part of the Left Renal Vein. The 'Urnierenvene' remains as the Spermatic Vein, which, therefore, consists of the lower part of the Left Post. Cardinal, between the entrance of the Spermatic Vein and the Left Common Iliac, normally degenerates; while the lower part of the Right Posterior Cardinal remains as the lower portion of the Inferior Vena Cava (fig. 2 B). The upper parts of the Post. Cardinals, above the transverse anastomosis, lose their connections with the lower portions, and remain as the Azygos and Hemiazygos system.

Now, if we consider the left kidney to have been prevented from reaching its proper height, then instead of the left Renal 
Vein going into the Left Posterior Cardinal at the level of the transverse anastomosis, it must have joined it some where below this point, and as this case shows, the Left Spermatic (Urnierenvene) was also low, and entered the Left Post. Cardinal below the renal (fig. $2 \mathrm{C}$ ). Therefore, that portion of the Left Posterior Cardinal, between the transverse anastomosis and the entrance of the Left Renal Vein, did not degenerate, but remained as a part of the Left Renal Vein, and when the kidney was displaced this long vein was carried across the aorta and under the Inferior Mesenteric Artery (fig. 2 C).

If we consider that the upper segment of the Left Subcardinal remains as the Left Suprarenal Vein, then it is possible to divide the Left Renal Vein in this specimen into four parts: part A (fig. 1) lies between the Inferior Vena Cava and the entrance of the Left Suprarenal Vein, and is the remains of the original anastomosis between the Right and Left Subcardinals (fig. 2 C); Portion B (fig. 1) is not definitely separated, but extends for a short distance distal to the Left Suprarenal Vein, and is the remains of the anastomosis between the Left Cardinal and Subcardinal (fig. $2 \mathrm{C}$ ); portion $\mathrm{C}$ (fig. 1) and also a small part of the Internal Spermatic, consists of that portion of the Left Posterior Cardinal which extended between the transverse anastomosis and the entrance of the Renal Vein (fig. $2 \mathrm{C}$ ) and on account of the low position of the Renal Vein did not undergo the normal degeneration; portion D (fig. 1) which lies distal to the entrance of the Internal Spermatic, is the original short Renal Vein (fig. 2 C). 


\section{BIBLIOGRAPHY}

1. Davis, L. M. 1910 Studies on the chief veins in early pig embryos and the origin of the vena cava inferior. Am. Jour. Anat., vol. 10, p. 461-472.

2. Evans, H. M. Human Embryology, vol. II, Keibel and Mall.

3. Hill, Eben C. 1906 On the embryonic development of a case of fused kidneys. Johns Hopkins Hosp. Bull., Vol. 17.

4. Hill, E. C. 1905 On the first appearance of the renal artery, and the relative development of the kidneys and wolffian body in pig embryos. Johns Hopkins Hosp. Bull., vol. 16.

5. JeIdell, H. 1911 A note on the source and character of the early blood vessels of the kidney. Anat. Rec., vol. 5.

6. MCMURRich, J. P. A case of crossed dystopia of the kidney with fusion. Jour. Anat. and Physiol., vol. 32.

7. Lewis, F. T. 1901-02 The development of the vena cava inferior. Amer. Jour. Anat., vol. 1.

8. Robinson, Byron. 1905 Congenital dislocation of the right kidney. Medical brief, vol. 33 . 